A common and widely distributed species found throughout New England from early July to late October in bushy pastures and barren grounds on dry upland soil.

\section{Scirtetica Sauss.}

Scirtetica Saussure I884. Prodromus Oedipodiorum, I35 (subg. nov.).

\section{Scirtetica marmorata Harr.} Figs. $27-27 \mathrm{~b}$.

Locusta marmorata. Harris, Report, p. 145, (1841); Treatise, 3 rd ed., I 79 .

Oedipoda marmorata. Scudder, 472 ; Smith, Conn., 372; Thomas, I I I.

Dissosteira marmorata. Saussure, I4I ; Fernald, 44.

Scirtettica marmorata. Morse, 105 ; Beutenmüller, 303.

Antenna : $\delta$, 10.5-1 $2.5 ; \%, 9.5-10.5$. H. fem. : $\delta, 9.3$-10.7; + , 10.5-12.5. Teg. : $\delta$, I7-20; $ᄋ, 20.5-22.5$. Body : ơ, 15-19; + , 22-25. Total length: ơ , $2 \mathrm{I} \cdot 5^{-25} ;$ ㅇ, 25-29 $\mathrm{mm}$.

While usually recognizable by the markings of the tegmina this species is extremely variable in color and widely so in markings even in the same locality, some examples being chiefly ashy, more or less maculate with black; others chiefly blackish fuscous, marked with white, yellowish, or reddish-brown; others again entirely bright rufous, sometimes of the tint of red hematite. It is one of the handsomest of our locusts, but next to Hippiscus rugosus is probably the least known of our Oedipodinae, since, though widely distributed, it is extremely local.

Like the species of the preceding genus it is a wide-awake and rather shy locust, best secured by marking down and cautiously approaching, capturing it with a swift sweep of the net as soon as within striking distance. Its stridulation and flight are very similar, perhaps indistinguishable, from those of Spharagemon bolli.

I have met with it in but three localities; in each of these it is common and is found on sandy barrens but scantily clothed with vegetation. My specimens were secured between the dates of Aug. 2 and Sept. 5 at Provincetown, Mass., West Chop, M. V., and North Haven, Ct.

\title{
NEW AND LITTLE-KNOWN COCCIDAE FROM FLORIDA.
}

\section{i. Determinations and Descriptions, including a new genus.}

$$
\text { BY T. D. A. COCKERELL, N. M. AGR. EXP. STA. }
$$

The Coccidae herein recorded were sent to me by Mr. A. L. Quaintance, who gives below the particulars as to their occurrence.
(1) Pseudophilippia, n. g. - A Lecaniine Coccid with, in the adult $q$, rudimentary legs and antennæ; secreting a profusion of cottony matter, which completely covers and hides it. Skin not chitinous. Apparently 
allied to Filippia (or Philippia) of Targioni Tozzetti, a European genus, which, however, has well-formed legs and antennae.

Pseudophilippia quaintancii, n. sp. - + Light yellow, bright yellow when boiled in caustic soda, drying brownish; oval or broad pyriform, about $2 \mathrm{~mm}$. long, secreting a mass of snow-white cottony material, about 4 by $3 \frac{1}{2} \mathrm{~mm}$., which completely covers and hides it.

Skin not chitinous; very thickly crowded on the dorsal surface with round glands. Antennae rudimentary, stout, little more than twice as long as broad, segments indistinct, sometimes there seem to be but two, of which the first is the longer; sometimes four, the first very short, the second longer, the third shorter than the second, the fourth about as long as the second, and beset with numerous bristles. The legs are small conical stout claw-like protuberances. Anal plates pale yellowish-brown, short and broad, with rounded ends; there is a finger-shaped chitinous process on each side of the anal ring, pointing candad. Anal ring with few bristles these stout.

A half-grown individual shows a few short simple marginal spines. In this the legs and antennae are rudimentary, practically as in the adult.

At bases of leaves of pine (Pinus), April 10, I897. (Quaintance No. 2.)

(2.) Lecanium parvicorne, n. sp. - + scale about $5 \mathrm{~mm}$. long, 4 broad and 3 high, of the ordinary Lecanium form, rather shiny; with irregular longitudinal series of conspicuous pits, one row on each side subdorsally, and two irregular and subconfluent rows laterally. Color of scale ochreous often with a pinkish tinge, with irregular black spots accompanying the rows of pits. Sometimes there are suffused blackish longitudinal bands in place of the spots. Under surface of $q$ dull pink.

The $q$, boiled in caustic soda, turns the liquid crimson. The eggs inside her turn bright crimson, strongly contrasting with her yellowish-brown skin. Mouth-parts very small for the size of the insect. Antennae short and broad, rudimentary, about $2 \frac{1}{2}$ times as long as broad, tipped with bristles, joints obscure. Legs equally rudimentary. Skin not tessellate, but with scattered gland-spots. The skin is very little chitinised, except in the anal region. I scales ordinary, granular, more or less overlapping.

Newly hatched larva oval, pale pinkish, with two very faint suffused longitudinal dorsal bands of darker color.

On twigs of pine (Pinus), April Io, 1897. (Quaintance No. 3.). A very distinct species, with austral affinities.

(3.) Lecanium tessellatum Sign., var. perforatum (Newst.). On leaves of Eugenia in greenhouse, (Quaintance, No. 5.). I will take this opportunity to refer again to the Jamaican species found on lignum-vitæ, which has been considered to be tessellatum. It is larger, and differs in some other particulars, for which see Tr. Am. Ent. Soc. XX. (I893) p. 5I. Since this Jamaican insect appears to be at least a distinct variety, I will call it var. Swainsonae, after the lady - an excellent entomologist - who first collected it.

(4.) Asterolecanium pustulans (Ckll.). On fig, April 5, 1897. (Quaintance, No. I.)

(5.) Aspidiotus perseae, Comst. On Magnolia, April I, I897. (Quaintance, No. 4.) The $q$ after laying eggs becomes reniform. On boiling the females, the contained embryos appear colorless, with large globules of the brightest orange imaginable. The $q$ becomes light yellow, the mouth-parts brownish; and the pygidium, and especially the lateral margins of the hindmost half of the body, remain deep reddish-brown, being chitinous. The dark chitinous margin is noticeable in the unboiled females. Newly hatched larva light orange. 


\section{i i. Biological Observations.}

BY A. L. QUAINTANCE, FLA. AGR. EXP. STA.

( I) Pseudophilippiaquaintancii.I first observed this insect April Ic, I 897, at Lake City, Florida. The topmost branches of a large pine (Pinus australis) that had recently been cut down was found to be badly infested. The insects were crowded thickly around the more tender growth, and from their abundant excretion of cottony substance were quite conspicuous for some distance away. Abundant honey-dew is excreted, which in some cases had formed a medium for the growth of "black fungi" (Meliola spp.). In several of these instances the entire cottony mass of a colony of these insects was quite black. Since this species was first noticed, it has been observed on quite young pines of the same species as above. It seems to be quite generally distributed in this locality.

(2) Lecanium parvicorne.-This insect has been collected from Pinus taeda and Pinus australis here at Lake City. A group of young pine trees ( $P$. taeda) were observed to be somewhat dwarfed and sickly. A close inspection revealed the presence of this scale in considerable numbers - possibly the cause of the stunted appearance of the trees. The adult scales inhabit the more terminal branches, probably last years growth. The young scales were crawling around in great abundance when first observed, April ro. At this date, April 22, they have become fixed, mainly to the tender shoots which have grown during the present year. These are frequently quite covered by them.

The scale has been found less abundantly on Pinus australis than on $P$. taeda. Professors Roelfs and Webber have observed this scale at Tallahassee, Florida.

(3) Lecanium tessellatum Sign., var. perforatum (Newst).-Collected from leaves of Eugenia jambos in the greenhouse of the Agric. Exp. Station. Plants infested were recently purchased from a nurseryman in the southern portion of the State.

(4) Asterolecanium pustulans.Sent in by a correspondent from Brevard Co. Fla., who reported it as very injurious to his fig trees. That this scale is very severe on the fig tree there can be but little doubt. Infested twigs were abnormally thickened, and covered thickly with shallow pits inhabited by the older scales. Scales of varying ages were to be observed on the same twig, from crawling young, to adults.

(5) Aspidiotus perseae.-Abundant on the lower surface of leaves of Magnolia glauca. More sparingly found on leaves of Ilex opaca. 

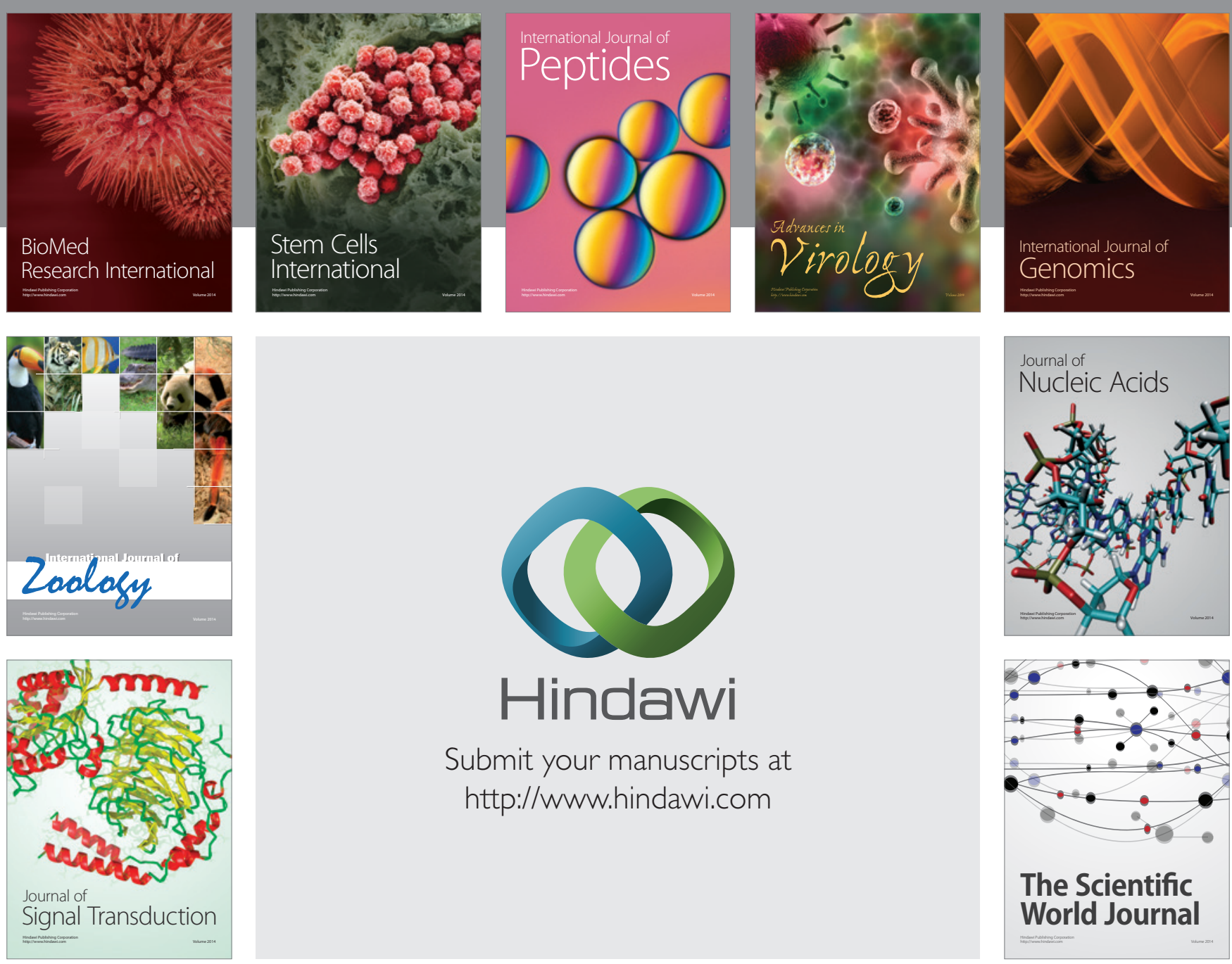

Submit your manuscripts at

http://www.hindawi.com
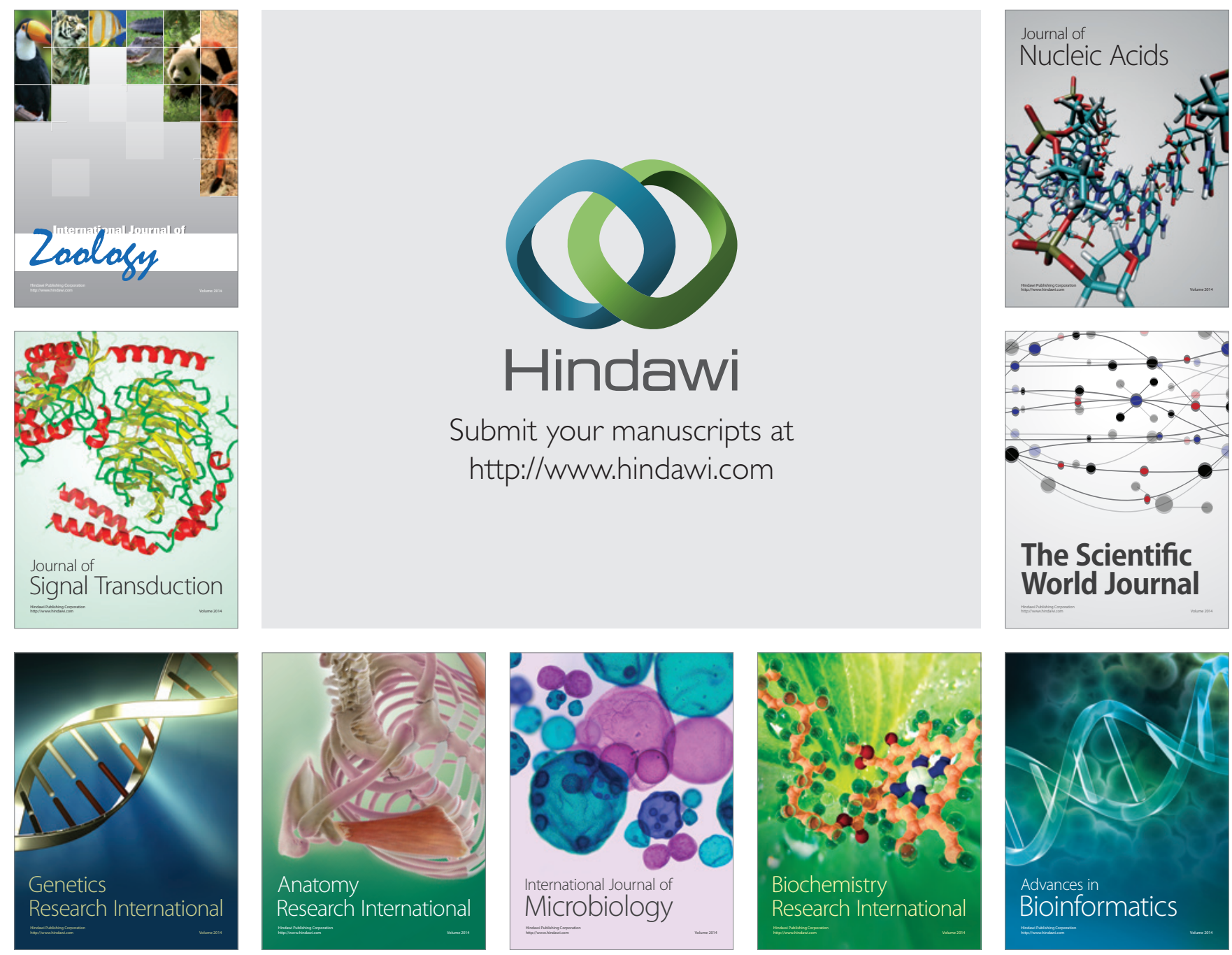

The Scientific World Journal
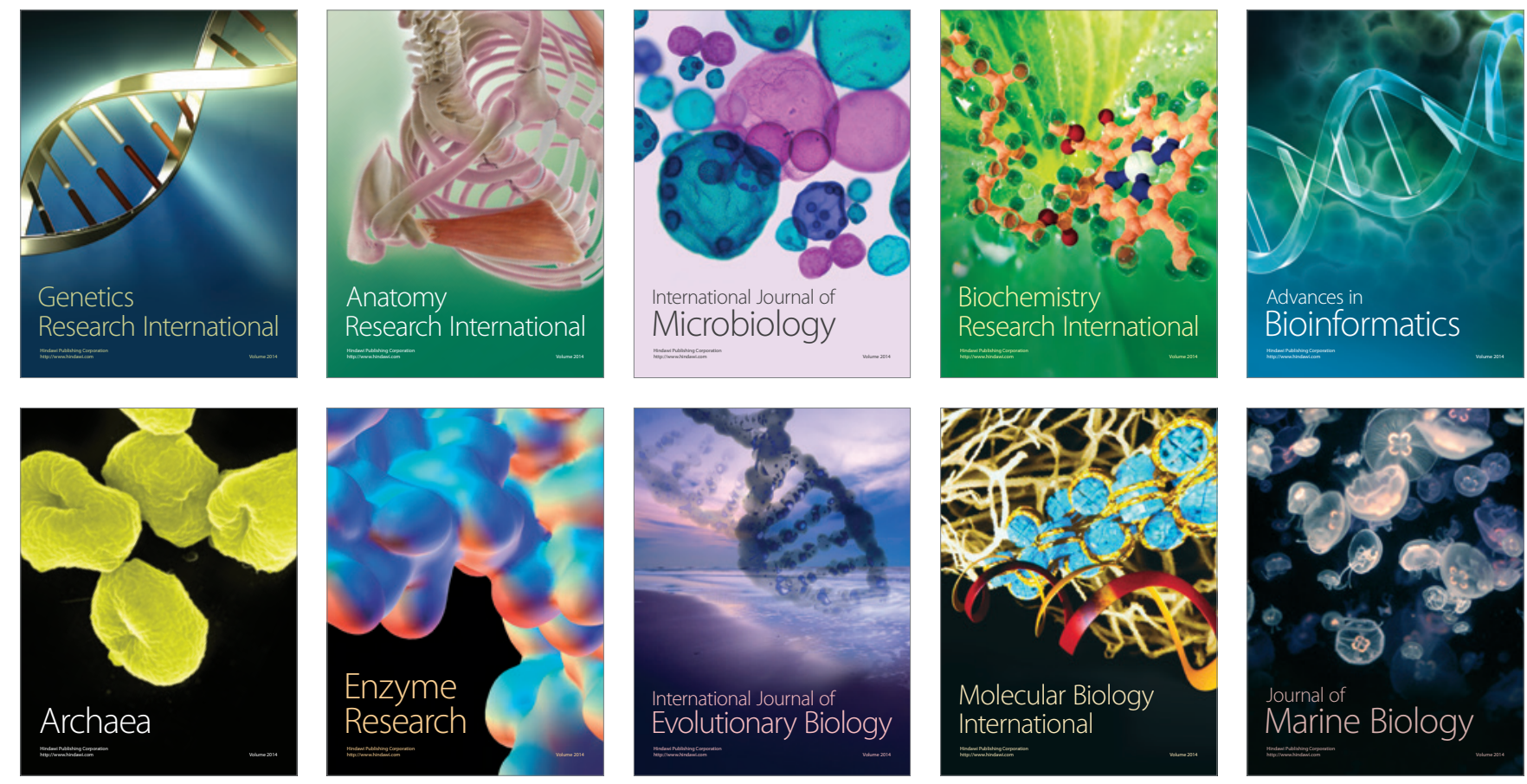